\title{
The Achromatic 'Philosophical Zombie', a Syndrome of Cerebral Achromatopsia with Color Anopsognosia
}

\author{
Antonio Carota ${ }^{a}$ Pasquale Calabrese ${ }^{b}$ \\ ${ }^{a}$ GSMN Neurocenter, Genolier Clinic, Genolier, and ${ }^{\mathrm{b}}$ Division of Molecular and Cognitive \\ Neuroscience, Basel University, Basel, Switzerland
}

\section{Key Words}

Achromatopsia · Color agnosia · Blindsight · Cerebral achromatopsia · Philosophical zombie · Color vision

\begin{abstract}
We describe a patient with persistent cerebral achromatopsia occurring after bilateral occipital strokes. Blinded color recognition was assessed with a computerized experimental paradigm and the patient reported the degree of confidence in the response exactness on a visual percent scale. Color recognition was accurate and above chance (Fisher's exact test, $p<0.002$ ). The degree of confidence in the answers showed a significant correlation with recognition scores (Spearman rank order correlation, $p<0.0001$ ). These findings constitute the exceptional condition of what we called color anopsognosia (not knowing of seeing colors) and recall the theoretic figure of the 'philosophical zombie'. However, the cognitive mechanisms of the dissociation between a subjective colorless vision and good performance for color naming still remain poorly understood.
\end{abstract}

\section{Introduction}

Seeing and being aware of seeing require both intact visual perception and adequate insight of that perception itself. Patients with central achromatopsia (color blindness) after a damage of the color area (V4 and related visual areas on the ventral occipital cortex [18BA]) report not seeing colors and that the external world appears to them as either completely black and white or in gray tonalities with different levels of brightness [1,2]. 
Blindsight is a kind of residual vision in patients with lesions of the primary visual (striate) cortex [3]. Blindsighters are able to make predictions, at above-chance levels, on the shape, location, color and movement or summation of visual stimuli in the blind fields $[3,4]$.

Some patients show remarkably accurate perceptual judgments despite lacking any perception, a condition that has also been termed agnosopsia (knowing without seeing) [5] or, according to our own definition, anopsognosia (not knowing of seeing; the term anopsognosia was suggested by the editor, J. Bogousslavsky). Unlike the blindsight condition (where usually the patient is completely unaware of the stimuli presented), agnosopsia or anopsognosia refers to a condition in which the patients have some conscious residual awareness of the stimuli presented although they insist not to experience seeing them as it is supposed to happen in normal people [5, 6].

We report the case of a patient with central achromatopsia showing features of color anopsognosia. We aimed to investigate the presence of blinded color recognition and the degree of confidence of the patient in color recognition, independently from neurophysiological mechanisms.

\section{Case History}

A 48-year-old right-handed man (A.J.) was submitted to surgical removal of a left olfactory groove meningioma of $6 \mathrm{~cm}$ in diameter, which manifested with abulia and unilateral anosmia. $24 \mathrm{~h}$ after surgery the patient's condition deteriorated as a consequence of an extended frontal hemorrhage. The hematoma produced mass effect, intracranial hypertension and bilateral strokes in the posterior cerebral artery (PCA). A bilateral frontal craniotomy was performed to evacuate the hematoma.

One year later, the patient was admitted to the neurologic ward because of partial complex epilepsy, which was successfully treated with carbamazepine. A.J. reported that neurologic deficits had been stable for many months. Since the acute phase of stroke, A.J.'s chief complaint had been colorless sight. MRI showed bilateral chronic frontal lesions (related to the meningioma removal and hemorrhage), and the chronic bilateral ischemic temporal-occipital lesions in the PCA territories (more prominent on the left) (fig. 1).

Neurological examination showed normal visual acuity, superior right quadranopsia and no other lateralization sign. Standardized neuropsychological assessment (Behavioral Assessment of the Dysexecutive Syndrome, Frontal Assessment Battery, Stroop Test, Word Fluency, Trail Making Test, Test of Everyday Attention, Rey-Osterrieth Auditory Verbal Learning Test, Rey Complex Figure Test, Boston Diagnostic Aphasia Examination, Clock Drawing Test, Hooper Visual Recognition Test, Visual Object and Space Perception Battery) revealed mild behavioral and cognitive signs of a dysexecutive syndrome (apathy, impulsivity, diminished mental speed, flexibility and working memory, reduction of phonological and categorical fluencies), moderate anterograde verbal and visual memory deficit (with retained responses to cues), mild anomia (more pronounced on proper names), signs of visual apperceptive agnosia (with spared recognition of forms, objects and faces) and achromatopsia.

Diagnosis of central achromatopsia was confirmed throughout the Farnsworth-Munsell 100-Hue Clinical Test [7], which assesses the ability to select an oddly colored patch embedded in an array of differently colored equiluminant hues. A.J.'s score with the Farnsworth test was 1,171, highly above the $95 \%$ confidence level of 100 for age 48 [8], suggesting that he performed pervasively randomly on color ordering. 
Carota et al.: The Achromatic 'Philosophical Zombie', a Syndrome of Cerebral

Achromatopsia with Color Anopsognosia

However, as generally reported with cerebral achromatopsia [9], A.J. was able to read Ishihara pseudoisochromatic plates, to perform tasks of mental and semantic color imagery and to name colors by description or by the vision of prototypical objects and drawings. We aimed to assess whether, despite the assumption of a total colorless vision, A.J. showed an unconscious color perception.

\section{Experiment}

At the center of a 17-inch computer screen $\left(200 \mathrm{~cd} / \mathrm{m}^{2}\right.$ brightness, $350: 1$ contrast ratio), on four different sessions, on a white background, A.J. viewed 550 fully colored circles of 12 $\mathrm{cm}$ in diameter ( 50 for each of the following colors: white, black, blue, brown, green, gray, orange, pink, red, violet, yellow). Colors were not equated for luminance. Each circle appeared randomly one by one after the patient's response without fixed time limits.

For each circle A.J. gave his response on a panel by indicating one of the written names of the eleven colors. For each stimulus the patient had to report the degree of confidence in the response exactness on a vertical visual percent scale (from $0=$ no confidence to $100=$ total confidence or absolute certainty).

\section{Results}

Although A.J. denied seeing colors or coloring tonalities for all the stimuli during all sessions, he gave a number of correct responses that was significantly above chance (table 1). The $p$ value was calculated with Fisher's exact test (one-tailed) against the probability of responding by chance (that is $1 / 11=9 \%$ ). A.J.'s degree of confidence in the exactness of his answers showed a significant correlation (Spearman rank order correlation) with recognition scores (table 1). Error analysis did not allow us to individuate specific patient's recognition patterns for the different colors.

\section{Discussion}

We report the case of a patient with cerebral achromatopsia after bilateral ventral occipital strokes (including the color area [V4] on the fusiform gyrus of the left hemisphere). This patient, although denying any color perception, was able to recognize several colors with good accuracy, much more significantly than what is expected by mere chance. We cannot indicate the neurophysiological mechanisms underlying this unconscious perception and whether luminance differences of the stimuli played a role in color recognition. Despite any patient argumentation and the largely insufficient performance with the FarnsworthMunsell 100-Hue Clinical Test, we cannot yet be completely sure that the patient did not retain any color perception as he stated.

However, the patient's condition appears to correspond to a form of agnosopsia (seeing without knowing) [5] or anopsognosia (not knowing of seeing) according to our definition. Thus, even if he showed significant confidence in the degree of exactness of color recognition, he reported lacking that subjective universal mental state (the so called 'qualia') of colors in which 'the color red is red'.

Our case recalls the classical description of the philosophical zombie (p-zombie) [10, 11], a hypothetical nonhuman being whose behavior is indistinguishable from that of a 
normal human being except for the absence of conscious experience. When a p-zombie is confronted with the color 'red', it does not have the experience of 'redness' but behaves exactly as if seeing red. An imaginary nonhysterical human being with a similar behavior instead has been defined in philosophical debates as a super-blindsighter [12].

The 'p-zombie' or 'super-blindsighter' phenomenology has been experimentally reproduced in normal subjects with transcranial magnetic stimulation (TMS) applied over the visual cortex [13]. TMS, right after presenting the visual stimulus, temporarily disrupts the visual cortex function by preventing visual inputs to reach visual awareness. However, despite the lack of sensorial awareness, remarkable abilities to detect color and other aspects of stimuli presented in the blind field can be retained with TMS stimulation [13].

There are convergent data from human and animal studies suggesting that blindsight is transmitted at the earliest stages of the vision process throughout subcortical retinotectal (i.e. superior colliculi) neuronal projections and by geniculate connections [14] to the extrastriate cortical occipital and parietal areas (dorsal stream) that are involved in the guidance of motion. Other studies suggested the role of compensatory processing of the spared primary visual cortex or, for color blindsight, spared ability to recognize simple stimulus features (as luminance) [15].

The theoretical existence of p-zombies and super-blindsighters has often been advanced in philosophical discussions on the mind-body problem, usually against forms of behaviorism, to support the role of subjective experience against observable behavior [10, 11].

However, the phenomenon of patients with cerebral lesions and anopsognosia gives, on the contrary, robust evidence to the conceivability of physical theories of the mind in order to account for those subjective 'extra-sensorial' experiences that are not explicable or permeable to the knowing self.

In the future, functional neuroimaging studies should be specifically designed for the exceptional cases of patients with color blindsight or anopsognosia. Ad hoc experimental visual recognition paradigms focusing on activation/deactivation of brain areas according to the degree of confidence of the patient in the behavioral performances, could provide further clues for the subjective and unconscious phenomenology of the 'qualia' in the domains of visual awareness and general consciousness of the self.

\section{Disclosure Statement}

The authors declare that the work described has not been published before, that it is not under consideration for publication anywhere else, that its publication has been approved by all co-authors and that figures, tables or text passages have not already been published elsewhere.

\section{References}

1 Damasio AR: Disorders of complex visual processing: agnosias, achromatopsia, Balint's syndrome, and related difficulties of orientation and construction; in Mesulam M-M (ed): Principles of Behavioral Neurology. Philadelphia, F.A. Davis Co., 1985, pp 259-289.

-2 Bouvier SE, Engel SA: Behavioral deficits and cortical damage loci in cerebral achromatopsia. Cereb Cortex 2006;16:183-191.

3 Weiskrantz L: Blindsight revisited. Curr Opin Neurobiol 1996;6:215-220.

4 Corbetta M, Marzi CA, Tassinari G, Aglioti S: Effectiveness of different task paradigms in revealing blindsight. Brain 1990;113:603-616.

5 Dankert J, Rossetti Y: Blindsight in action: what can the different sub-types of blindsight tell us about the control of visually guided actions? Neurosci Biobehav Rev 2005;29:1035-1046. 
6 Overgaard M: Seeing without seeing? Degraded conscious vision in a blindsight patient. PLoS One 2008;3:e3028.

7 Farnsworth D: The Farnsworth-Munsell 100-Hue Test for the examination of color discrimination. Revised. Maryland, Munsell Color Company Inc., 1957.

8 Kinnear PR, Sahraie A: New Farnsworth-Munsell 100 hue test norms of normal observers for each year of age 5-22 and for age decades 30-70. Br J Ophthalmol 2002;86:1408-1411.

-9 Short RA, Graff-Radford NR: Localization of hemiachromatopsia. Neurocase 2001;7:331-337.

10 Kirk R: 'Zombies'; in Zalta NE (ed): The Stanford Encyclopedia of Philosophy. Summer 2011 Edition. http://plato.stanford.edu/archives/spr2011/entries/zombies/.

11 Harnad S: Minds, machines, and Turing: the indistinguishability of indistinguishables. J Log Lang Inf 2000;9:425-445.

12 Dennet DC: Consciousness Explained. Boston, Little, Brown and Company, 1991.

-13 Boyer JL, Harrison S, Ro T: Unconscious processing of orientation and color without primary visual cortex. Proc Natl Acad Sci USA 2005;102:16875-16879.

14 Schmid MC, Mrowka SW, Turchi J, Saunders RC, Wilke M, Peters AJ, Ye FQ Leopold DA: Blindsight depends on the lateral geniculate nucleus. Nature 2010;466:373-377.

15 Alexander I, Cowey A: Edges, colour and awareness in blindsight. Conscious Cogn 2010;19:520-533.

Table 1. Mean color recognition scores and the percent degree of confidence in the exactness of responses

\begin{tabular}{|c|c|c|c|c|c|c|}
\hline \multirow[t]{3}{*}{ Colors } & \multicolumn{2}{|c|}{ Correct naming responses } & \multicolumn{4}{|c|}{ Degree of confidence in the response } \\
\hline & \multirow[t]{2}{*}{$\%$} & \multirow[t]{2}{*}{ p value* } & \multicolumn{2}{|c|}{ mean $\pm 1 \mathrm{SD}$} & \multirow[t]{2}{*}{ correlation** } & \multirow[t]{2}{*}{$\mathrm{p}$ value** } \\
\hline & & & exact & false & & \\
\hline White & 98 & $<0.0001$ & $68.0 \pm 7.4$ & $35.0 \pm 14.0$ & 0.57 & $<0.0001$ \\
\hline Yellow & 92 & $<0.0001$ & $64.7 \pm 15.9$ & $37.0 \pm 11.4$ & 0.46 & $<0.0001$ \\
\hline Black & 80 & $<0.0001$ & $63.1 \pm 12$ & $39.0 \pm 16.6$ & 0.53 & $<0.0001$ \\
\hline Blue & 54 & $<0.0001$ & $50.2 \pm 13.3$ & $25.5 \pm 8.9$ & 0.74 & $<0.0001$ \\
\hline Green & 42 & 0.0002 & $35.2 \pm 10.7$ & $16.0 \pm 10.8$ & 0.64 & $<0.0001$ \\
\hline Red & 38 & 0.001 & $28.7 \pm 15.8$ & $17.6 \pm 14.9$ & 0.32 & 0.002 \\
\hline Orange & 36 & 0.002 & $20.0 \pm 15.7$ & $14.2 \pm 12.8$ & 0.15 & 0.027 \\
\hline Brown & 24 & 0.0542 & $16.1 \pm 10.6$ & $13.5 \pm 10.7$ & 0.01 & 0.10 \\
\hline Gray & 20 & 0.1312 & $12.0 \pm 11.4$ & $9.4 \pm 10.7$ & 0.01 & 0.09 \\
\hline Violet & 16 & 0.2728 & $5.0 \pm 7.1$ & $10.5 \pm 7.4$ & -0.15 & 0.002 \\
\hline Pink & 12 & 0.5 & $6.7 \pm 5.2$ & $11.9 \pm 10.8$ & -0.16 & 0.047 \\
\hline
\end{tabular}

* The p value was calculated with the Fisher's exact test (one-tailed) against the probability of responding by chance (that is $1 / 11=9 \%$ ). ${ }^{* *}$ Correlation coefficient (and $\mathrm{p}$ value) between naming responses (correct or false) and the degree of confidence in the exactness of the responses (either when they reveal to be correct or false) were calculated with the Spearman rank order. 


\section{Case Reports in Neurology}

\begin{tabular}{l|l}
\hline Case Rep Neurol 2013;5:98-103 \\
\hline DOI: 10.1159/000351027 & $\begin{array}{l}\text { C 2013 S. Karger AG, Basel } \\
\text { www.karger.com/crn }\end{array}$ \\
\hline
\end{tabular}

Carota et al.: The Achromatic 'Philosophical Zombie', a Syndrome of Cerebral Achromatopsia with Color Anopsognosia

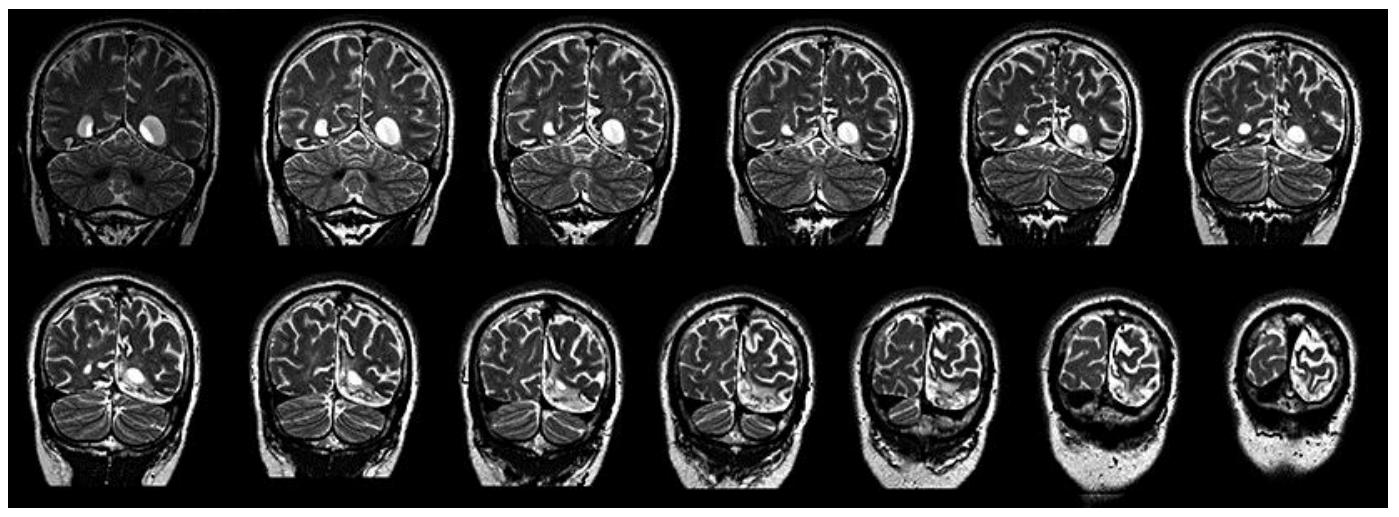

Fig. 1. T2 MRI coronal sections (from front to back) showing the bilateral ischemic temporal-occipital lesions in the PCA territories (more prominent on the left) involving the color area. 